\title{
Growth of $\mathrm{CdO}$ films from $\mathrm{CdO}_{2}$ films by chemical bath deposition: Influence of the concentration of cadmium precursor
}

\author{
Campos-Gonzalez E., Guillén-Cervantes A.", Santoyo-Salazar J., Zelaya-Angel O. \\ Departamento de Física, CINVESTAV-IPN, Apdo. Postal 14-740, México D.F. 07360, México \\ Ramírez-Velázquez L. E. \\ Escuela Superior de Ingeniería Química e Industrias Extractivas del IPN, México D.F., México \\ Santos-Cruz J., Mayén-Hernández S.A., de Moure-Flores F. \\ Facultad de Química, Materiales, Universidad Autónoma de Querétaro, Querétaro, 76010, México \\ Olvera M. de la L. \\ Departamento de Ingeniería Eléctrica, Sección de Estado Sólido, CINVESTAV-IPN \\ Apdo. Postal 14-740, México D.F. 07360, México \\ Contreras-Puente G. \\ Escuela Superior de Física y Matemáticas del IPN, México D.F. 07738, México \\ (Recibido: 20 de enero de 2015; Aceptado: 2 de marzo de 2015)
}

\begin{abstract}
Cadmium peroxide films were grown by chemical bath deposition on glass slides at $50{ }^{\circ} \mathrm{C}$ using $\mathrm{CdCl}_{2}$ as cadmium source. Films were deposited at different nominal cadmium concentrations. As-grown films were annealed in air at $300{ }^{\circ} \mathrm{C}$ for obtaining cadmium oxide thin films. The structural, morphological, optical and compositional properties of $\mathrm{CdO}$ films were analyzed in terms of the cadmium nominal composition and the annealing effect.
\end{abstract}

Keywords: CdO films; Cadmium peroxide; Chemical bath deposition; Heat treatment

\section{Introduction}

Transparent conducting oxide thin films have important applications in the opto-electronics field as transparent electrodes [1], liquid crystal displays, IR detectors, thin film solar cells [2], etc. Cadmium oxide is an $n$-type semiconductor with a high mobility at room temperature ( $216 \mathrm{~cm}^{2} \mathrm{~V}^{-1} \mathrm{~s}^{-1}$ ) and a bandgap value calculated in $2.18 \mathrm{eV}$ [3], properties that make this material ideal for solar cells applications. $\mathrm{CdO}$ films can be prepared by different techniques, such as sputtering, metal organic chemical vapor deposition, ion beam sputtering, sol-gel, spray pyrolysis, chemical bath deposition (CBD) among others. For synthesizing $\mathrm{CdO}$ films by $\mathrm{CBD}$, first $\mathrm{CdO}_{2}$ or $\mathrm{Cd}(\mathrm{OH})_{2}$ films are obtained and subsequently are subjected to a heat treatment $[2,4]$. In this work, we report on the influence of the cadmium nominal concentration in the $\mathrm{CdO}_{2}$ formation by $\mathrm{CBD}$, and the formation of $\mathrm{CdO}$ by annealing in air.

\section{Experimental details}

\subsection{Films growth}

The $\mathrm{CdO}_{2}$ films were deposited on glass substrates by CBD at a bath temperature of $50{ }^{\circ} \mathrm{C}$ for $1 \mathrm{~h}$. Before growth, substrates were cleaned in ultrasonic bath for 5 min by rinsing in successive steps in xylenes, ethanol, acetone and distilled water. The reaction solution was prepared mixing $40 \mathrm{ml}$ of $\mathrm{CdCl}_{2}, 20 \mathrm{ml}$ of ammonium hydroxide $\left(\mathrm{NH}_{4} \mathrm{OH}\right)$ and $2 \mathrm{ml}$ of $\mathrm{H}_{2} \mathrm{O}_{2} . \mathrm{CdO}_{2}$ films were deposited varying the $\mathrm{CdCl}_{2}$ concentration in: $0.030 \mathrm{M}, 0.035 \mathrm{M}$ and $0.040 \mathrm{M}$. DI water $(18 \mathrm{M} \Omega)$ was used for the preparation of the solutions. The $\mathrm{pH}$ of bath was 11.5. After deposition, the films were rinsed in distilled water in ultrasonic bath and dried with nitrogen. Then, the as-grown films were heated at $300{ }^{\circ} \mathrm{C}$ in air by $1 \mathrm{~h}$. As-grown $\mathrm{CdO}_{2}$ films were labeled from low to high $\mathrm{CdCl}_{2}$ concentration as: CD-01, CD-02 and CD-03 (see Table 1) whereas after the heat treatment samples were labeled CD-01-HT, CD-02-HT and CD-03HT, respectively, (see Table 2).

\subsection{Characterization}

$\mathrm{X}$-ray diffraction (XRD) patterns were obtained in a Rigaku Smartlab diffractometer, using the $\mathrm{Cu}-\mathrm{K} \alpha$ line $(1.5406 \AA)$. Electron diffraction patterns from selected areas were obtained by transmission electron microscopy (TEM) using a JEOL JEM 2010 microscope operating at $200 \mathrm{kV}$. Film thicknesses were measured in a KLA Tencor P15 profilometer. The topography studies were performed by Atomic Force Microscopy (AFM), using a ThermoMicroscope Autoprobe CP (Veeco Instruments) in contact mode. A Perkin-Elmer Lambda $25 \mathrm{UV}-\mathrm{Vis}$ 

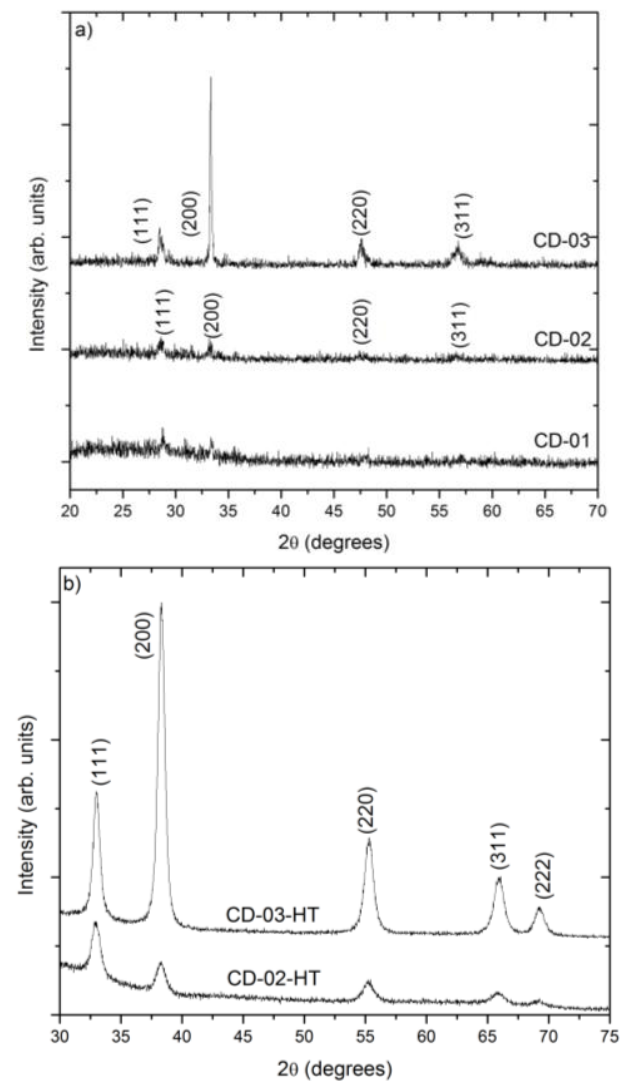

Figure 1. $\mathrm{XRD}$ patterns of a) $\mathrm{CdO}_{2}$ films grown by $\mathrm{CBD}$ and b) $\mathrm{CdO}$ thin films, produced after annealing the $\mathrm{CdO}_{2}$ films.
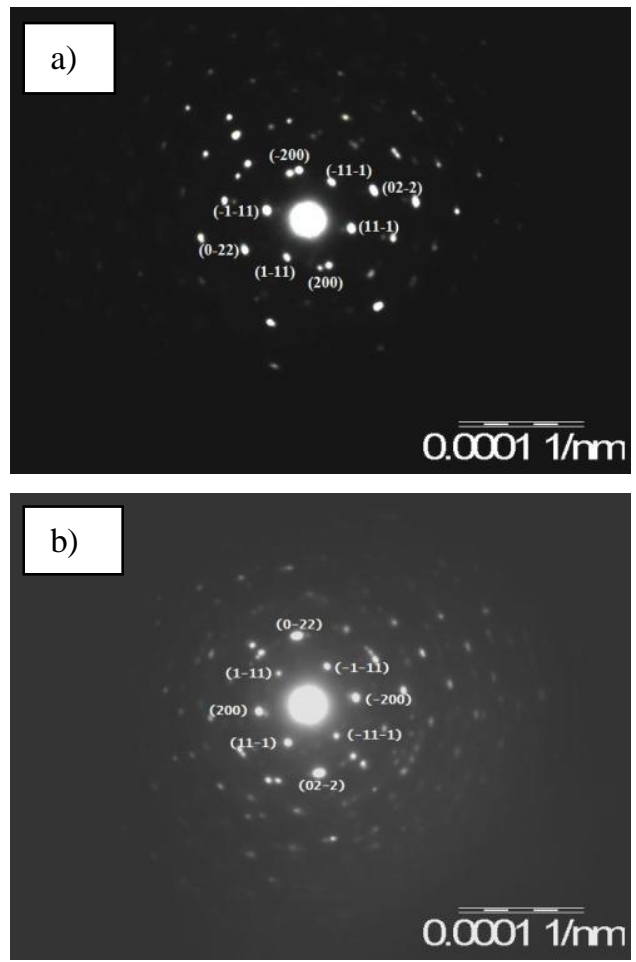

Figure 2. Diffraction patterns of a film deposited with a $0.040 \mathrm{M} \mathrm{CdCl}_{2}$ concentration; a) $\mathrm{CdO}_{2}$ as-grown sample and b) after annealing.
Table 1. Physical properties of as-grown $\mathrm{CdO}_{2}$ films.

\begin{tabular}{lccc}
\hline Sample & $\begin{array}{c}{\left[\mathbf{C d C l}_{2}\right]} \\
(\mathrm{M})\end{array}$ & $\begin{array}{c}\text { Thickness } \\
(\mathrm{nm})\end{array}$ & $\begin{array}{c}\boldsymbol{E}_{\boldsymbol{g}} \\
(\mathrm{eV})\end{array}$ \\
\hline $\mathrm{CD}-01$ & 0.030 & 136 & 3.98 \\
$\mathrm{CD}-02$ & 0.035 & 386 & 3.95 \\
$\mathrm{CD}-03$ & 0.040 & 573 & 3.82 \\
\hline
\end{tabular}

Table 2. Physical properties of CdO films (annealed films).

\begin{tabular}{lclll}
\hline \multicolumn{1}{c}{ Sample } & $\begin{array}{c}{\left[\mathbf{C d C l}_{2}\right]} \\
(\mathrm{M})\end{array}$ & $\begin{array}{c}\text { Thickness } \\
(\mathrm{nm})\end{array}$ & $\begin{array}{c}\text { Thickness } \\
\text { evaporated } \\
(\mathrm{nm})\end{array}$ & $\begin{array}{c}\boldsymbol{E}_{\boldsymbol{g}} \\
(\mathrm{eV})\end{array}$ \\
\hline $\begin{array}{l}\text { CD-01- } \\
\text { HT }\end{array}$ & 0.030 & 0 & 136 & - \\
$\begin{array}{l}\text { CD-02- } \\
\text { HT }\end{array}$ & 0.035 & 130 & 256 & 2.38 \\
$\begin{array}{l}\text { CD-03- } \\
\text { HT }\end{array}$ & 0.040 & 291 & 282 & 2.59 \\
\hline
\end{tabular}

spectrophotometer was used to obtain optical transmittance. Atomic concentration measurements of films were determined by Energy Dispersive Spectrometry (EDS) with a Bruker 5010 XFlash detector installed in a Jeol JSM-6300 scanning electron microscope.

\section{Results and discussion}

\subsection{Structural characterization}

XRD patterns of as-grown films are shown in Fig. 1a). The CD-01 and CD-02 samples have two diffraction peaks of low intensity at $28.46^{\circ}$ and $33.32^{\circ}$. The CD-03 sample presents four diffraction peaks at $28.46^{\circ}, 33.32^{\circ}, 47.66^{\circ}$ and $56.76^{\circ}$. These peaks correspond to the cubic $\mathrm{CdO}_{2}$ (cadmium peroxide) phase and the diffraction planes are (111), (200), (220) and (311), respectively. The peaks were indexed using the powder diffraction files 39-1221 (PDF\#39-1221). From Fig. 1a) it is noted that the crystalline quality improves as the $\mathrm{CdCl}_{2}$ concentration increases in the bath, indicating that the increase of the $\mathrm{CdCl}_{2}$ concentration promotes the formation of the $\mathrm{CdO}_{2}$ compound.

Fig. 1b) shows the XRD patterns of films after the heat treatment at $300{ }^{\circ} \mathrm{C}$ in air. Five diffraction peaks at $32.98^{\circ}$, $38.34^{\circ}, 55.32^{\circ}, 66.06^{\circ}$ and $69.22^{\circ}$ are distinguished, whose diffraction planes are (111), (200), (220), (311) and (222), respectively. These diffraction planes correspond to the cubic $\mathrm{CdO}$. The peaks were indexed using the PDF\#011049. It is important to mention that during the annealing, the CD-01 sample was totally evaporated. This indicates that an important amount of material evaporates during the annealing. Fig. 2 shows the transmission electron diffraction patterns of CD-03 sample before and after annealing. The electron beam incides into the [011] zone axis. The diffraction planes are indicated in Fig. 2. The electron diffraction patterns confirm that the CD-03 and 
CD-03-HT samples have a cubic structure; in fact, these samples have an fcc crystalline structure.

As mentioned before, heat treatment desorbs the films surface. In order to know the evaporation rates, thickness measurements were performed. Table 1 shows the thickness of as-grown $\mathrm{CdO}_{2}$ films. The film thickness increases with the $\mathrm{CdCl}_{2}$ concentration, suggesting that the increase of the $\mathrm{Cd}$ nominal concentration promotes the formation of material, in agreement with XRD analysis in Fig. 1a). Table 2 displays the thickness of the samples. The CD-01 sample was evaporated during the annealing so that the thickness of the CD-01-HT film was zero. Note from Tables 1 and 2 that during the heat treatment a great amount of material evaporates. The thicknesses evaporated (summarized in Table 2), from CD-01, CD-02 and CD-03 were $136 \mathrm{~nm}, 256 \mathrm{~nm}$ and $282 \mathrm{~nm}$, respectively.

Due to the high amount of material evaporated, the topography of samples after heat treatment must change drastically. In order to know the topography of the films AFM measurements were carried out. The surface morphology of films is shown in Fig. 3. AFM images corresponding to the as-grown $\mathrm{CdO}_{2}$ films are displayed in the left column, whereas those of $\mathrm{CdO}$ films (annealed films) are placed in the right column. The surface of the CD-01 sample (Fig.3 a) shows holes, which indicates that for a $0.030 \mathrm{M} \mathrm{CdCl}$ concentration the formation of the $\mathrm{CdO}_{2}$ film begins. The surface morphology of CD-02 sample is shown in Fig. 3b). This sample has large clusters of around $500 \mathrm{~nm}$. Comparing images CD-02 and CD-HT02 (Figs. 3b and 3d) there is no significant difference between the two surfaces. However, differences between the surfaces of the CD-03 and CD-HT-03 samples are notable. Fig. 3c) displays the surface of the CD-03 sample, showing grains of irregular shape, distributed in a periodic array. These grains decrease in dimensions after heating the sample as corroborated in Fig. 3e). The optical properties of the $\mathrm{CdO}$ samples are strongly related to the size of these grains. In the following paragraphs, we will further discuss this idea.

Fig. 4a) shows the transmittance spectra of as-grown $\mathrm{CdO}_{2}$ films. The CD-01 and CD-02 samples present absorption of light in the wavelength region $\geq 400 \mathrm{~nm}$, which can be attributed to crystalline defects, that are responsible of the reduction of transmittance [5]. The CD03 sample has a high transmittance in the visible region $(>70 \%)$ and the spectrum presents an absorption edge practically vertical, indicating a good crystalline quality of the sample (in agreement with the XRD results). The transmittance spectra of films with heat treatment are shown in Fig. 4b). Note that the heat treatment reduces the transmittance of films and shifts the absorption edge towards the yellow. From these spectra the absorption coefficient $(\alpha)$ was calculated by the relation: $T=(1-R)^{2} \exp (-\alpha d)$, where $T$ is the transmittance, $R$ the reflectance and $d$ the film thickness [5]. The absorption coefficient was used to determine the bandgap $\left(E_{g}\right)$ of

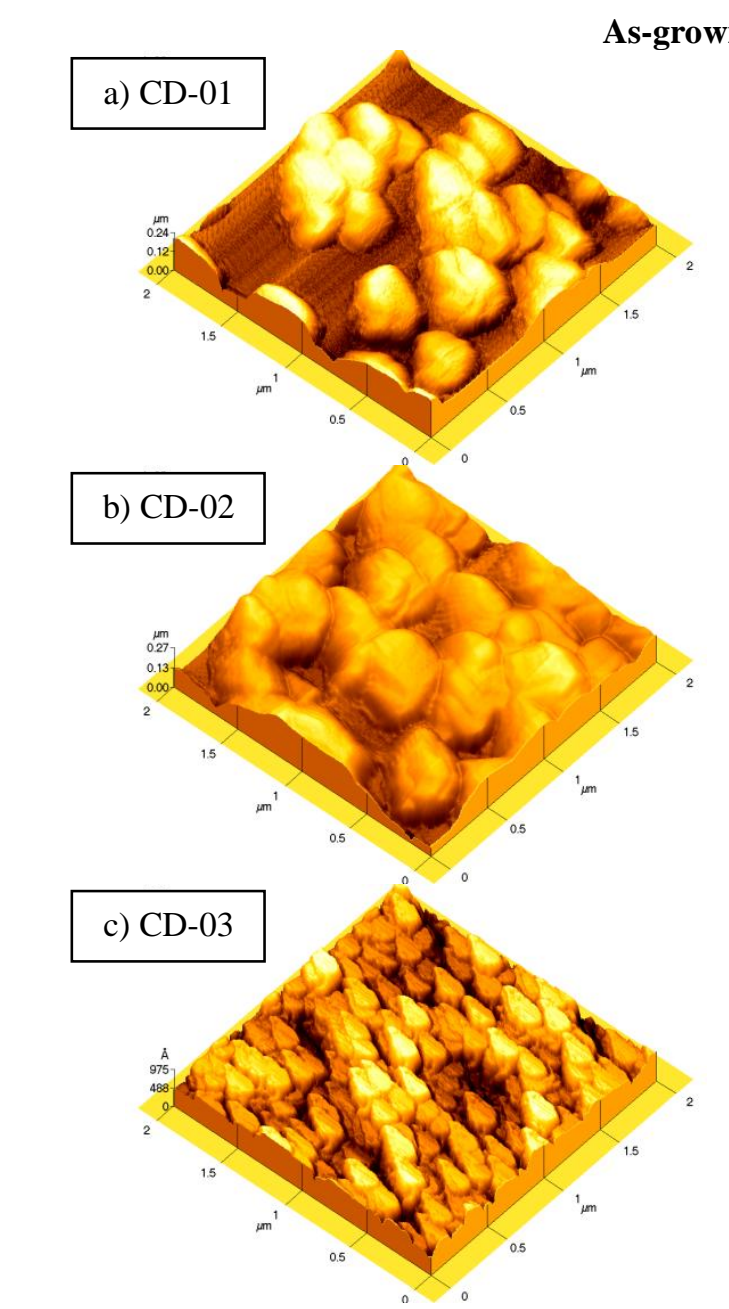

As-grown films
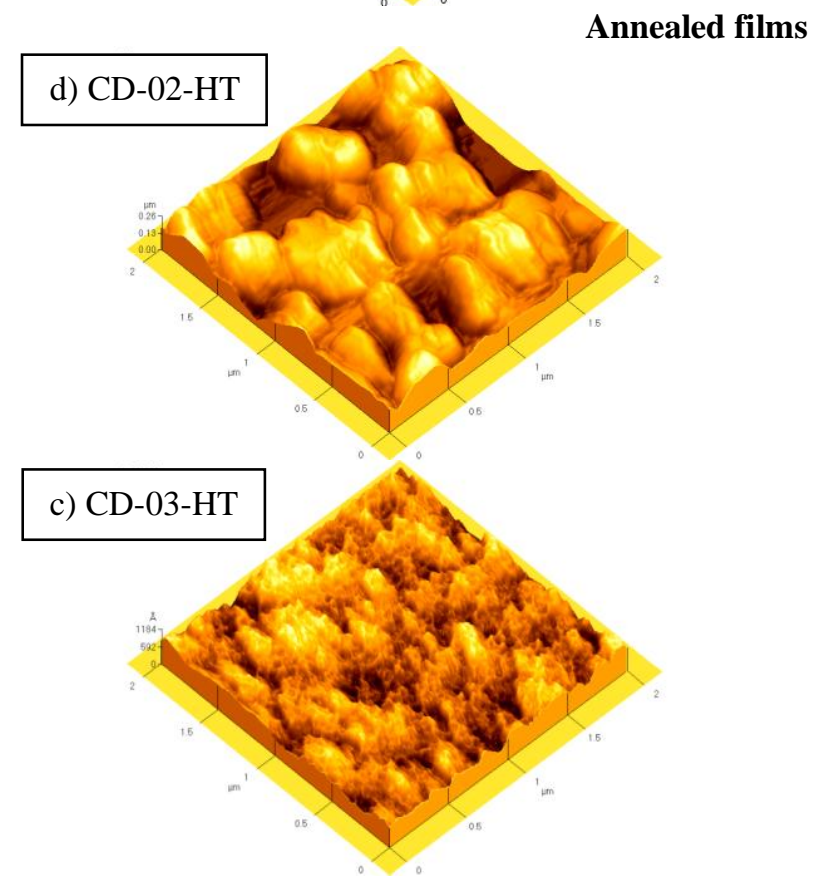

Figure 3. AFM images of as-grown $\mathrm{CdO}_{2}(\mathrm{a}, \mathrm{b}, \mathrm{c})$ and annealed $(\mathrm{CdO})(\mathrm{d}$, e) films, respectively. 

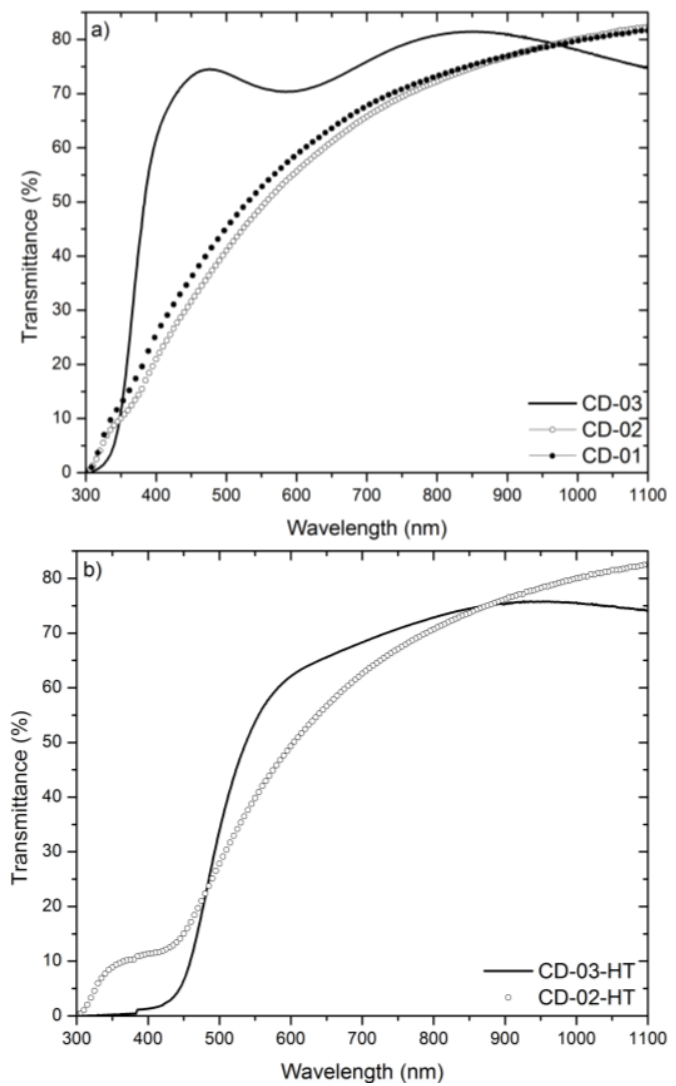

Figure 4. Transmittance spectra of a) as-grown $\mathrm{CdO}_{2}$ and b) $\mathrm{CdO}$ films.
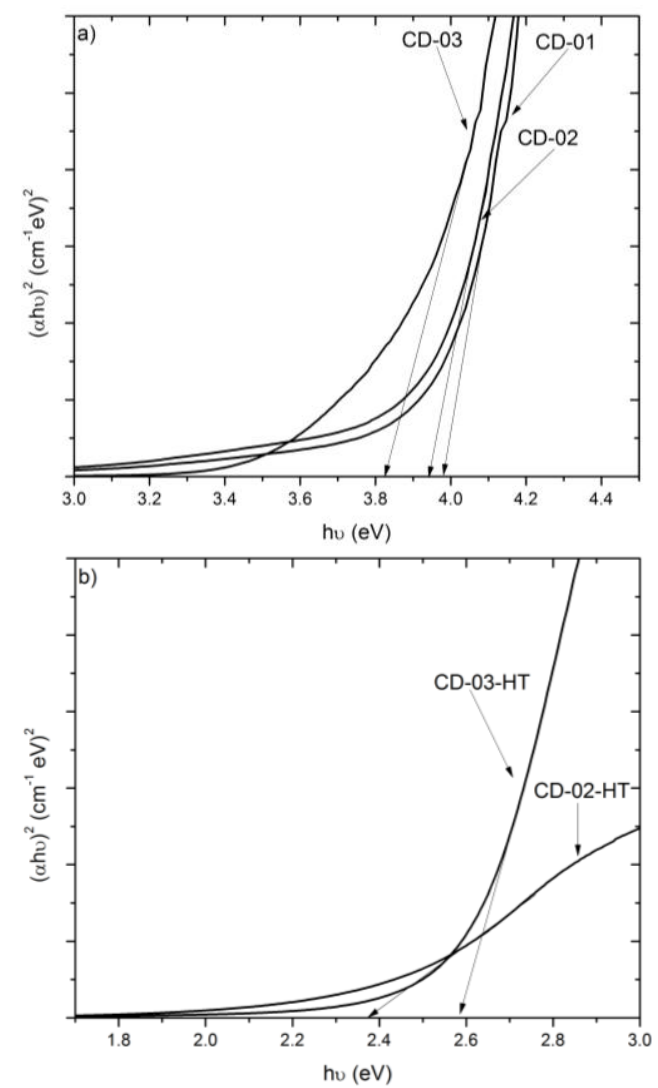

Figure 5. Bandgap calculations of a) $\mathrm{CdO}_{2}$ films and b) $\mathrm{CdO}$ films.
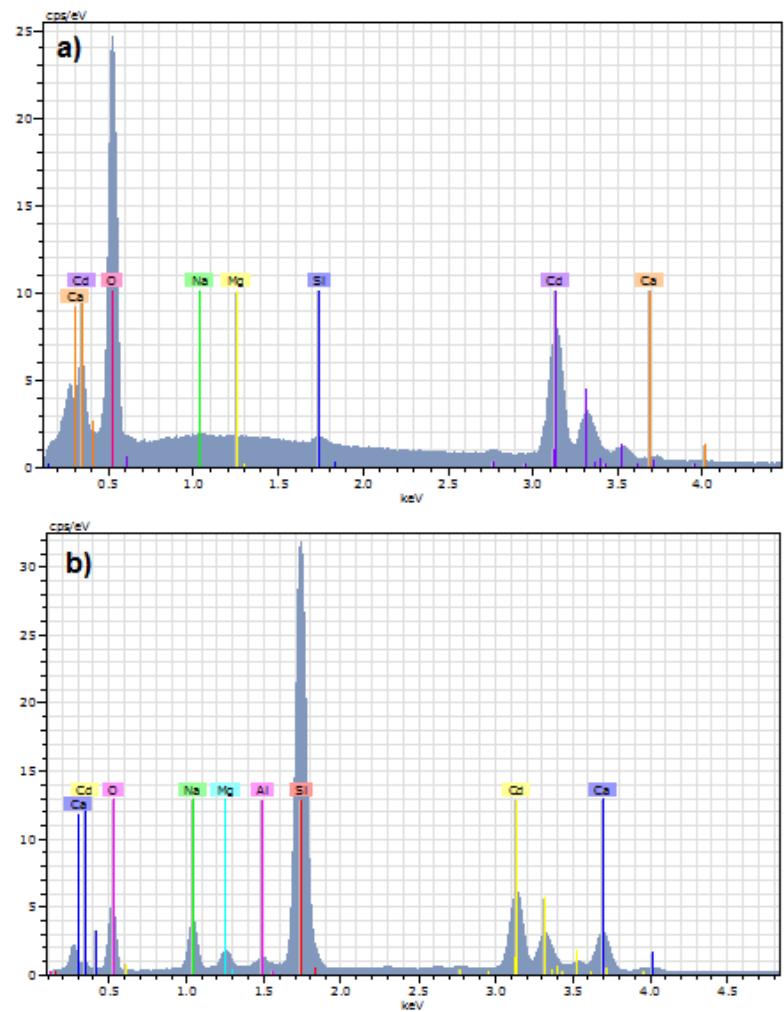

Figure 6. EDS spectra of CD-03 and CD-03-HT samples deposited with a $0.040 \mathrm{M} \mathrm{CdCl}_{2}$ concentration: a) as-grown $\mathrm{CdO}_{2}$ film and b) $\mathrm{CdO}$ thin film.

films, using the relation $\alpha h v=\left(h v-E_{g}\right)^{1 / 2}$, where $h v$ is the photon energy [1,5]. Fig 5 shows the graphic of $(\alpha h v)^{2}$ vs $h v$, the $E_{g}$ was determined by fitting the lineal part of the curve. The bandgap values of the as-grown $\mathrm{CdO}_{2}$ films are compiled in Table 1, the bandgap value decreases from $3.98 \mathrm{eV}$ to $3.82 \mathrm{eV}$ as the $\mathrm{CdCl}_{2}$ concentration in the bath increases. The $E_{g}$ value calculated for $\mathrm{CdO}$ films; CD-02HT and CD-03-HT, was $2.38 \mathrm{eV}$ and $2.59 \mathrm{eV}$ (see Table $2)$, respectively, in agreement with the bandgap values reported in the literature [6]. Pan et al. [7] reported that the grain size decrease in $\mathrm{CdO}$ samples produces an increase in their bandgap. Encompassing the same consideration the AFM images of Figs. 3d) and 3e) show that $\mathrm{CdO}$ surface grains decrease_from sample CD-02-HT to CD-03-HT. We infer that the grain decrease observed by AFM is responsible of the bandgap widening in our samples synthesized with the highest concentration of $\mathrm{CdCl}_{2}$, suggesting that the molar concentration has strong influence in the grain size. This result will be subject of another publication concerning electrical properties of the samples. The increase in the bandgap has been explained in terms of the Burstein-Moss effect as long as the intrinsic physical properties of $\mathrm{CdO}$ samples $[7,8]$.

Fig. 6a) and Fig. 6b) show the EDS spectra of CD-03 and CD-03-HT samples, respectively. Peaks associated to cadmium $(\mathrm{Cd})$, oxygen $(\mathrm{O})$, sodium $(\mathrm{Na})$, magnesium $(\mathrm{Mg})$, silicon $(\mathrm{Si})$ and calcium $(\mathrm{Ca})$ are indicated. 
In Fig. 6a) peaks corresponding to $\mathrm{Ca}, \mathrm{Si}, \mathrm{Mg}$ and $\mathrm{Na}$ are of low intensity, while those associated to $\mathrm{Cd}$ and $\mathrm{O}$ are of high intensity. Peaks of low intensity are due to substrate, whereas detected peaks of $\mathrm{Cd}$ and $\mathrm{O}$ correspond to the $\mathrm{CdO}_{2}$ compound formation. The oxygen peak is about three times more intense than that corresponding to cadmium; this is because a fraction of the oxygen detected corresponds to the substrate. Fig. $6 \mathrm{~b}$ ) shows the spectrum of CD-03-HT. After annealing the intensity of peaks corresponding to the substrate increases, due to the reduction of film thickness by evaporation. In spite the intensity of cadmium and oxygen peaks decreases after annealing, Fig. 6b) shows $\mathrm{Cd}$ and $\mathrm{O}$ signals are similar in intensity, suggesting the $\mathrm{CdO}$ compound formation.

\section{Conclusions}

Cadmium peroxide $\left(\mathrm{CdO}_{2}\right)$ films were obtained by $\mathrm{CBD}$ using $\mathrm{CdCl}_{2}$ as cadmium source. The physical properties were analyzed as a function of $\mathrm{CdCl}_{2}$ concentration. X-ray diffraction showed that $\mathrm{CdO}_{2}$ films have the cubic stable phase. The structural, morphological and compositional characterization showed that the increase of the $\mathrm{CdCl}_{2}$ concentration promotes the formation of $\mathrm{CdO}_{2}$ compound. For a $0.040 \mathrm{M} \mathrm{CdCl}_{2}$ concentration $\mathrm{CdO}_{2}$ films with a high crystalline quality were obtained. $\mathrm{CdO}_{2}$ films were annealed in air at $300{ }^{\circ} \mathrm{C}$ for obtaining $\mathrm{CdO}$ films. The structural characterization of the annealed films showed that $\mathrm{CdO}$ samples have cubic structure. Bandgap values of 2.38 and $2.59 \mathrm{eV}$ were estimated from optical characterization. This widening in the bandgap was explained in terms of the Burstein-Moss effect.

\section{Acknowledgments}

We acknowledge the technical support of Marcela Guerrero, Rogelio Fragoso, Paulina González Arceo, Zacarías Rivera and Benito Ortega.

The authors acknowledge financial support for this work from FONDO SECTORIAL CONACYT-SENERSUSTENTABILIDAD ENERGÉTICA through CeMIEsol, within of the strategic project number 37; "Development of new photovoltaic devices and semisuperconductor materials".

\section{References}

[1]. F. de Moure-Flores, J.G. Quiñones-Galván, A. HernándezHernández, A. Guillén-Cervantes, M.A. Santana-Aranda, M. de la L. Olvera, M. Meléndez-Lira, Appl. Surf. Sci. 258, 2459 (2012).

[2]. M. Ocampo, A. M. Fernandez, P. J. Sebastian, Semicond. Sci. Technol. 8, 750 (1993).

[3]. S. K. Vasheghani Farahani, V. Muñoz-Sanjosé, J. ZúñigaPérez, C. F. McConville, and T. D. Veal, Appl. Phys. Lett. 102, 022102 (2013).

[4]. Hani Khallaf, Chia-Ta Chen, Liann-Be Chang, Oleg Lupan, Aniruddha Dutta, Helge Heinrich, A. Shenouda, Lee Choww, Appl. Surf. Sci. 257, 9237 (2011).

[5]. F. de Moure-Flores, K.E. Nieto-Zepeda, S. Gallardo, J.G. Quiñones-Galván, A. Hernández-Hernández, A. GuillénCervantes, M. Zapata-Torres, M. de la L. Olvera, M. MeléndezLira, J. Phys. Chem. Solids 74, 611 (2013).

[6]. L.R. de León-Gutiérrez, J.J. Cayente-Romero, J.M. PezaTapia, E Barrera-Calva, J.C. Martínez-Flores, M. Ortega-López, Matt. Lett. 60, 3866 (2006).

[7]. L. L. Pan, G. Y. Li, S. S. Xiao, L. Zhao, and J. S. Lian, J. Mat. Sci.: Mat. Elect. 25, 1003 (2014).

[8]. N. Ueda, H. Maeda, H. Hosono, and H. Kawazoe, J. Appl. Phys. 84, 6174 (1998). 